\title{
Orofacial adverse effects of COVID-19 vaccines exist but are rare
}

\author{
Ahmad Sofi-Mahmudi' \\ A commentary on \\ Cirillo N. \\ Reported orofacial adverse effects of COVID-19 vaccines: the knowns \\ and the unknowns. J Oral Pathol Med 2021; 50: 424-427.
}

\section{Practice points}

- Official documents from the EU, UK, US and Canada regarding adverse effects of mRNA-based COVID-19 vaccines show that they may be related to rare orofacial complications.

- These orofacial complications include swelling of the face, lips, or tongue, Bell's palsy and, exclusively with the mRNA-1273 vaccine, swelling of the face in people who have had a facial cosmetic injection.

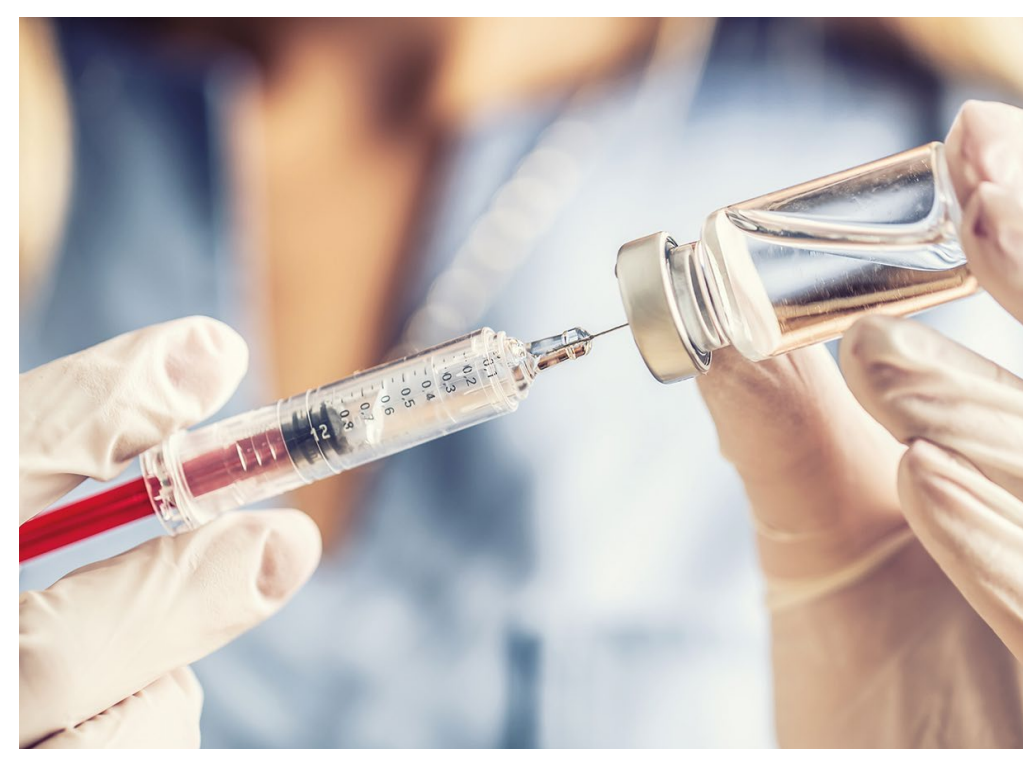

So far, there has been some information available regarding the adverse effects of the COVID-19 vaccines as they have not been tested in long-term use and phase IV clinical trials. Accordingly, both their safety and effectiveness are still under investigation. With emerging evidence that some COVID-19 vaccines may have links with some life-threatening adverse events, ${ }^{4,5,6,7}$ people are more concerned about the safety of these vaccines, although the harms are very much fewer than the benefits. ${ }^{8,9}$

Cirillo ${ }^{10}$ tried to collect all official information about COVID19-related adverse events in the orofacial region. Instead of using statistical data, this study analysed the contents of product monographs, product information and consumer medicine information for the BNT162b2 (Pfizer-BioNTech) and mRNA-1273 (Moderna) vaccines from some official regulatory authorities, namely the US Food and Drug Administration (FDA), Health Canada, European Medicines Agency (EMA)/European Commission and UK's Medicines and Healthcare products Regulatory Agency (MHRA). The results of this study showed that these materials pointed out some rare orofacial adverse effects, including swelling of the face, lips or tongue (up to 1 in 1,000 people), facial drooping (Bell's palsy) and, exclusively with the mRNA-1273 vaccine, swelling of the face in people who 
have had a facial cosmetic injection. These side effects were not reported similarly in all official documents; for example, Bell's palsy was not mentioned in the information for patients in the US and Canada.

Although this method provides us with valuable information from trusted documents, there is a need for more accurate and quantitative methods regarding orofacial adverse effects of COVID-19 vaccines with valid national/international data. There have been some efforts recently in European countries. ${ }^{11}$

While all these documents are based on the high-quality largescale phase III clinical trials, due to the inconsistencies in the description of these adverse effects, the overall quality of the result of this study was judged to be low. This means we need more highquality and long-term research regarding the adverse effects of COVID-19 vaccines in the orofacial region. Until then, we should know that mRNA-based COVID-19 vaccines may be related to orofacial region swelling and Bell's palsy.

\section{Author affiliation}

${ }^{1}$ National Institute for Medical Research Development, Tehran, Iran.

Correspondence to: Ahmad Sofi-Mahmudi

\section{References}

1. Butler R, MacDonald N E. Diagnosing the determinants of vaccine hesitancy in specific subgroups: The Guide to Tailoring Immunization Programmes (TIP). Vaccine 2015; 33: 4176-4179.

2. Harrison E A, Wu J W. Vaccine confidence in the time of COVID-19. Eur J Epidemiol 2020; 35: 325-330.

3. Dror A A, Eisenbach N, Taiber $S$ et al. Vaccine hesitancy: the next challenge in the fight against COVID-19. Eur J Epidemiol 2020; 35: 775-779.

4. Greinacher A, Thiele T, Warkentin T E, Weisser K, Kyrle P A, Eichinger S. Thrombotic Thrombocytopenia after ChAdOx1 nCov-19 Vaccination. N Engl / Med 2021; DOI: 10.1056/NEJMoa2104840.

5. Schultz N H, Sørvoll I H, Michelsen A E et al. Thrombosis and Thrombocytopenia after ChAdOx1 nCoV-19 Vaccination. N Engl J Med 2021; DOI: 10.1056/ NEJMoa2104882.

6. Scully M, Singh D, Lown R et al. Pathologic Antibodies to Platelet Factor 4 after ChAdOx1 nCoV-19 Vaccination. N Engl J Med 2021; DOI: 10.1056/ NEJMoa2105385.

7. Muir K L, Kallam A, Koepsell S A, Gundabolu K. Thrombotic Thrombocytopenia after Ad26.COV2.S Vaccination. N Engl / Med 2021; DOI: 10.1056/NEJMc2105869.

8. Mahase E. AstraZeneca vaccine: Blood clots are "extremely rare" and benefits outweigh risks, regulators conclude. BMJ 2021; DOI: 10.1136/bmj.n931.

9. Taquet M, Husain M, Geddes J R, Luciano S, Harrison P J. Cerebral venous thrombosis: a retrospective cohort study of 513,284 confirmed COVID-19 cases and a comparison with 489,871 people receiving a COVID-19 mRNA vaccine. 2021

10. Cirillo N. Reported orofacial adverse effects of COVID-19 vaccines: The knowns and the unknowns. J Oral Pathol Med 2021; 50: 424-427.

11. Riad A, Koscik M, Attia S, Conrad J, Mekhemar M, Hocková B. Oral Side Effects of COVID-19 Vaccine. 2021. Available at https://clinicaltrials.gov/ct2/show/ NCT04706156 (accessed May 2021).

Evidence-Based Dentistry (2021) 22, 70-71.

https://doi.org/ 10.1038/s41432-021-0178-y 